\title{
Ceratose liquenóide em um cão
}

\author{
Lichenoid keratosis in a dog \\ Tatiana Mello de Souza ${ }^{\mathrm{I}}$ Rafael Almeida Fighera ${ }^{\mathrm{II}}$ Claudete Schmidt ${ }^{\mathrm{II}}$ \\ Claudio Severo Lombardo de Barros ${ }^{\text {II }}$
}

\begin{abstract}
A ceratose liquenóide é uma rara dermatopatia proliferativa descrita em humanos e cães. Nos cães, a doença caracteriza-se pelo aparecimento de placas hiperceratóticas bem circunscritas nas pinas $e$, menos freqüentemente, nas virilhas. Este artigo descreve um caso de ceratose liquenóide em um cão macho, Dobermann, de seis anos de idade, com lesões verrucosas e multifocais na face interna das orelhas $e$ lesões alopécicas, hiperpigmentadas, levemente elevadas e descamativas nas axilas e virilhas, ambas com evolução de aproximadamente três meses. O diagnóstico foi realizado com base na associação entre os achados clínicos e histopatológicos.

Palavras-chave: doenças de cães, ceratose liquenóide, doenças hiperplásicas da epiderme, doenças liquenóides da derme, dermatologia, dermatopatologia.
\end{abstract}

\section{ABSTRACT}

Lichenoid keratosis is a rare proliferative dermatopathy reported in human beings and dogs. In dogs the disease is characterized by well circumscribed hyperkeratotic plaques distributed in the skin of pinnae and, less frequently, in the inguinal region. This report describes a case of lichenoid keratosis in a six-year-old male Dobermann dog which had multifocal verrucous lesions in the internal aspect of the pinnae and slightly scaly, overpigmented alopecic lesions in the axillae and inguinal region; both lesions had a clinical course of approximately three months. The diagnosis was based on the association of the clinical and histopathological findings.
Key words: diseases of dogs, lichenoid keratosis, hyperplasic diseases of the epidermis, lichenoid diseases of the dermis, dermatology, dermatopathology.

A ceratose liquenóide é uma rara dermatopatia descrita em cães (ANDERSON et al., 1989) que se assemelha a uma comum dermatopatia humana denominada ceratose liquenóide benigna (SHAPIRO \& ACKERMAN, 1966). Os cães afetados são adultos e aparentemente a doença não apresenta predisposição por raça ou sexo (ANDERSON et al., 1989). Clinicamente, os cães afetados demonstram lesões proliferativas na forma de placas bem circunscritas ou como projeções verrucosas de 0,5 a 2,0cm de diâmetro nas orelhas, preferencialmente nas pinas (ANDERSON et al., 1989). Ocasionalmente, essas lesões podem ser eritematosas ou hiperpigmentadas e localizadas nas virilhas (GROSS et al., 2005). Tais lesões podem ser muito semelhantes à dermatose psoriasiformeliquenóide e à dermatose liquenóide idiopática (YAGER \& WILCOCK, 1994).

Histologicamente, a ceratose liquenóide canina se caracteriza por uma proliferação epidérmica do tipo irregular ou psoriasiforme associada à inflamação linfoplasmocitária que oblitera a junção dermoepidérmica, um aspecto típico de dermatite

\footnotetext{
IPrograma de Pós-graduação em Medicina Veterinária, Universidade Federal de Santa Maria (UFSM), 97105-900, Santa Maria, RS, Brasil. E-mail: teitsouza@yahoo.com.br. Autor para correspondência.

"Laboratório de Patologia Veterinária, Departamento de Patologia, UFSM, Santa Maria, RS, Brasil.

IIIDepartamento de Clínica de Pequenos Animais, UFSM, Santa Maria, RS, Brasil.
} 
liquenóide (ANDERSON et al., 1989). Outros achados incluem hipergranulose, hiperceratose ortoceratótica, hiperceratose paraceratótica, incontinência pigmentar, formação de crostas serocelulares e, menos freqüentemente, formação de pústulas intraepidérmicas (ANDERSON et al., 1989; YAGER \& WILCOCK, 1994; GROSS et al., 2005).

Em humanos, a expressão ceratose liquenóide é utilizada para descrever duas doenças distintas, a ceratose liquenóide benigna (CLB) e a ceratose liquenóide crônica. A CLB, também denominada ceratose liquenóide semelhante ao líquen plano (SHAPIRO \& ACKERMAN, 1966), é considerada comum e afeta preferencialmente o tronco e os membros superiores (PRIETO et al., 1993). Clinicamente, a doença caracteriza-se pelo surgimento de lesões solitárias, nãopruriginosas e na forma de máculas, pápulas ou placas, lisas ou verrucosas, por vezes eritematosas ou hiperpigmentadas (SCOTT \& JOHNSON, 1976), que freqüentemente regridem de forma espontânea (MORGAN et al., 2005). Histologicamente, tais lesões caracterizam-se por um infiltrado inflamatório liquenóide crônico constituído principalmente por linfócitos (SHAPIRO \& ACKERMAN, 1966). De acordo com a presença ou ausência de outras lesões, a CLB é classificada em cinco tipos: clássico, bolhoso, atípico, interfacial e atrófico (MORGAN et al., 2005).

Embora a ceratose liquenóide canina tenha sido reconhecida há quase 20 anos (ANDERSON et al., 1989) e esteja citada em alguns livros-texto de dermatologia (SCOTT et al., 2001) e dermatopatologia veterinária (YAGER \& WILCOCK, 1994; GROSS et al., 2005), não se conhecem outros relatos na literatura dermatológica desde então. Com base nesses aspectos, este relato tem os objetivos de descrever um caso de ceratose liquenóide em um cão, discutir os principais diagnósticos diferenciais e comparar essa doença com aquela descrita em humanos.

Um cão macho, Dobermann, de seis anos de idade, com história clínica de lesão de pele nas orelhas, axilas e virilhas há aproximadamente três meses, foi atendido no Hospital Veterinário da Universidade Federal de Santa Maria (UFSM). Ao exame clínico, o animal apresentava lesões verrucosas, marrom-claras e multifocais, que variavam de 0,3 a 1,5cm de diâmetro na face interna de ambas as orelhas (Figura 1A), e lesões alopécicas, hiperpigmentadas, levemente elevadas e descamativas nas axilas e virilhas. O cão foi submetido à biópsia incisional de pele da orelha e virilha. O material obtido foi encaminhado ao Laboratório de Patologia Veterinária da UFSM e processado rotineiramente.

Na histologia de ambas as amostras, havia aumento acentuado no número de camadas da epiderme, que, em várias áreas, projetava-se para dentro da derme superficial na forma de cristas de rede longas e desiguais (acantose irregular), ocasionalmente unidas pelas bases (acantose psoriasiforme). Em algumas seções havia áreas focalmente extensas de espessamento da epiderme em decorrência de moderado aumento no número de camadas do estrato granuloso (hipergranulose). O estrato córneo era abundante e se dispunha difusamente na forma de tramas de cesto (hiperceratose ortoceratótica). Em algumas áreas multifocais, o estrato córneo era espesso, compacto e mantinha seus núcleos (hiperceratose paraceratótica). Na derme superficial, logo abaixo da epiderme, havia acentuado infiltrado inflamatório constituído basicamente por pequenos linfócitos não-clivados e plasmócitos (dermatite liquenóide). Em muitas áreas, essas células formavam uma espessa banda que obscurecia totalmente a junção dermoepidérmica e em várias regiões da epiderme era possível observar linfócitos entre os ceratinócitos epidérmicos (exocitose linfocitária). Áreas esparsas demonstravam cavidades bolhosas subepidérmicas e intra-epidérmicas variavelmente preenchidas por células inflamatórias, principalmente por pequenos linfócitos e, ocasionalmente, por alguns poucos neutrófilos degenerados (Figura 1B). Outros achados incluíram edema intercelular moderado e, nos cortes da pele da virilha, acentuada hiperpigmentação e incontinência pigmentar. Com base nos achados clínicos e histopatológicos, foi feito o diagnóstico de ceratose liquenóide. Não foi recomendado nenhum tipo de tratamento clínico.

Doenças hiperplásicas da epiderme são um grupo importante de distúrbios cutâneos de cães, já doenças liquenóides da derme são um grupo incomum de distúrbios cutâneos de cães (GROSS et al., 2005). Dentre todas essas doenças hiperplásicas e liquenóides, a ceratose liquenóide é a mais rara e a menos descrita em artigos científicos na literatura internacional. Os diagnósticos diferenciais de ceratose liquenóide em cães devem incluir todas as doenças hiperplásicas da epiderme e liquenóides da derme, mas principalmente a dermatose psoriasiforme-liquenóide (DPL) e a dermatose liquenóide idiopática (DLI), duas condições com as quais apresenta estreita semelhança clinicopatológica (YAGER \& WILCOCK, 1994).

A DPL é uma doença rara e idiopática da pele que afeta cães, principalmente os Springer Spaniel (GROSS et al., 1986). As lesões macroscópicas e histológicas dessa doença são muito semelhantes às observadas nesse caso; entretanto, sua distribuição não se restringe às pinas e virilhas, pois freqüentemente ocorre também ao redor da boca e dos olhos, no 


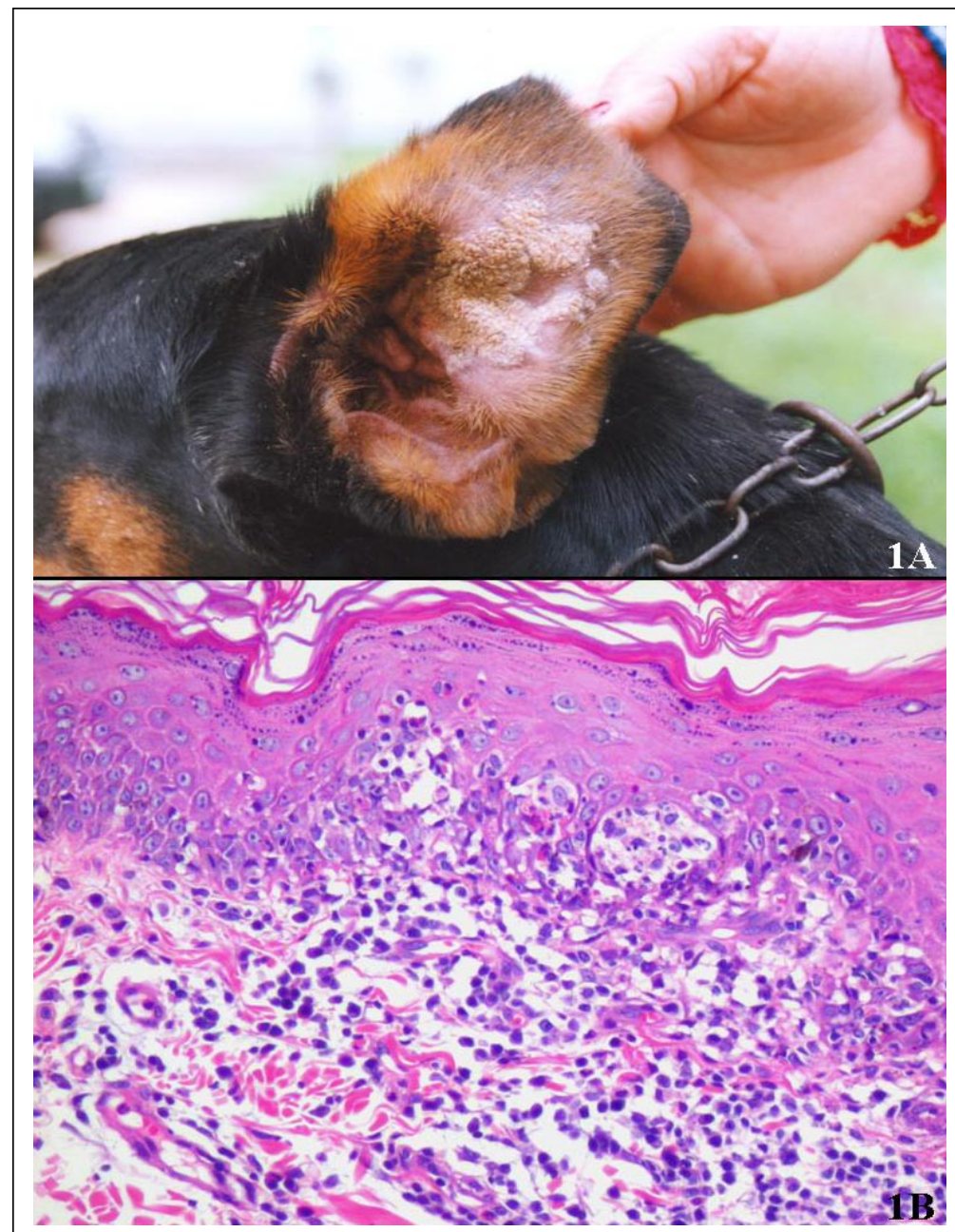

Figura 1 - Ceratose liquenóide, pele, cão. A) Placas verrucosas, marrom-claras, multifocais a coalescentes na face interna da orelha esquerda. Lesão idêntica era observada na face interna da orelha direita. B) Denso infiltrado inflamatório que oblitera a junção dermo-epidérmica, o típico aspecto de dermatite liquenóide. O infiltrado inflamatório é constituído principalmente por pequenos linfócitos não-clivados e moderada quantidade de plasmócitos. Observe o intenso epiteliotropismo, os acúmulos de linfócitos entre os ceratinócitos na epiderme acantótica e as grandes cavidades bolhosas subepidérmicas parcialmente preenchidas por linfócitos e alguns poucos neutrófilos degenerados.

abdômen ventral, no prepúcio e no períneo (MASON et al., 1986). Essa distribuição tem sido utilizada como um critério essencial na diferenciação dessas duas condições (GROSS et al., 2005). Além disso, diferentemente da ceratose liquenóide, na DPL, as lesões são mais eritematosas do que hiperpigmentadas, ocorrem em cães jovens (antes de um ano e meio de idade) e quase sempre da raça Springer Spaniel (YAGER \& WILCOCK, 1994).

A DLI é uma rara condição dermatológica que afeta cães e gatos e se caracteriza clinicamente pelo aparecimento de pápulas e placas liquenificadas distribuídas aleatoriamente pela pele de todo o corpo (BUERGER \& SCOTT, 1988). As lesões histológicas da DLI são semelhantes às observadas no cão deste relato. No entanto, uma característica chave na sua diferenciação para com ceratose liquenóide é a não ocorrência de acantose proeminente (SCOTT et al., 1984). Além disso, diferentemente da ceratose liquenóide, na DLI, as lesões são aleatórias, não se restringindo às pinas e virilhas (YAGER \& WILCOCK, 1994).

Os sinais clínicos e os achados histopatológicos do caso ora relatado são idênticos 
àqueles descritos para ceratose liquenóide em cães (ANDERSON et al., 1989) e constituem evidências que permitem o diagnóstico (GROSS et al., 2005). Em humanos, dentro da classificação da ceratose liquenóide, casos que apresentam acantose, dermatite liquenóide e paraceratose são considerados como pertencendo ao padrão típico (PRIETO et al., 1993). No caso aqui descrito, havia, além dessas lesões, formação de cavidades bolhosas subepidérmicas e intraepidérmicas, um dos aspectos histopatológicos que em dermatopatologia humana classifica a acantose liquenóide como pertencendo ao tipo bolhoso (MORGAN et al., 2005). Entretanto, diferentemente do que ocorre em humanos com essa forma da doença, não havia necrose dos ceratinócitos basais.

Embora a ceratose liquenóide seja uma dermatopatia rara, suas características peculiares permitem uma suspeita clínica e um fácil diagnóstico histológico. Além disso, como essa lesão não responde a nenhum tratamento clínico conhecido e regride espontaneamente (ANDERSON et al., 1989), é fundamental que os clínicos de pequenos animais reconheçam essa condição para distingui-la de outras doenças dermatológicas que requerem tratamentos apropriados.

\section{APRESENTAÇÃo}

Este trabalho é parte da tese de doutorado do primeiro autor.

\section{REFERÊNCIAS}

ANDERSON, W.I. et al. Idiopathic benign lichenoid keratosis on the pinna of the ear in four dogs. Cornell Veterinary, v.79, n.2, p.179-184, 1989.
BUERGER, R.G.; SCOTT, D.W. Lichenoid dermatitis in a cat: a case report. Journal of the American Animal Hospital Association, v.24, p.55-59, 1988.

GROSS, T.L. et al. Psoriasiform lichenoid dermatitis in the springer spaniels. Veterinary Pathology, v.23, n.1, p.76-78, 1986.

GROSS, T.L. et al. Skin diseases of the dog and cat. Clinical and histopathologic diagnosis. 2.ed. Oxford: Blackwell, 2005. 932p.

MASON, K.V. et al. Characterization of lichenoid-psoriasiform dermatosis of springer spaniels. Journal of the American Veterinary Medical Association, v.189, n.8, p.897-901, 1986.

MORGAN, M.B. et al. Benign lichenoid keratosis: a clinical and pathologic reappraisal of 1040 cases. American Journal of Dermatopathology, v.27, n.8, p.387-392, 2005.

PRIETO, V.G. et al. Lichen planus-like keratosis. A clinical and histologic reexamination. American Journal of Surgical Pathology, v.17, p.259-263, 1993.

SCOTT, D.W. Lichenoid reactions in the skin of dogs: clinicopathologic correlations. Journal of the American Animal Hospital Association, v.20, p.305-317, 1984.

SCOTT, D.W. et al. Muller \& Kirk - Small animal dermatology. 6.ed. Philadelphia: Saunders, 2001. 1528p.

SCOTT, M.A.; JOHNSON, W.C. Lichenoid benign keratosis. Journal of Cutaneous Pathology, v.3, p.217-221, 1976.

SHAPIRO, L.; ACKERMAN, A.B. Solitary lichen-planus like keratosis. Dermatologica, v.132, p.386-389, 1966.

YAGER, J.A.; WILCOCK, B.P. Color atlas and text of surgical pathology of the dog and cat. Dermatopathology and skin tumors. London: Wolfe, 1994. 320p. 